\title{
Performance of rice straw fiber improving the drying of waste activated sludge
}

\author{
Xue $\mathrm{Li}^{1}$, Lingyu Wang ${ }^{1}$, Jing Huang ${ }^{2 a}$, Huishuang $\mathrm{Yi}^{1}$, Zhiming Xu${ }^{1}$, Hao Zhou ${ }^{1}$ \\ ${ }^{1}$ College of Biological and Environmental Engineering, Changsha University, ChangSha 410022, China \\ ${ }^{2}$ Hunan Academy of Forestry and State Key Laboratory of Utilization of Woody Oil Resource, Changsha 410004, China
}

\begin{abstract}
The high moisture content of the excess sludge in the sewage treatment plant has brought great difficulties to the subsequent treatment. In this study, rice straw fiber was collected as a conditioner for adding to the sludge. The effect of different grain diameter and dosages of straw fiber on sludge drying efficiency were investigated under different temperatures. Drying temperature is one of the most important factors affecting sludge drying rate. Compared with the original sludge, the drying efficiency of sludge adding rice straw fiber was higher. The effect of 35-80 straw fiber was 20\%, and the water content decreased from about $70 \%$ to less than $10 \%$. The effect of straw fiber particle size on sludge drying is affected by temperature, and the particle size should be taken into account at low temperature.
\end{abstract}

\section{Introduction}

In recent years, with the increasing demand for municipal sewage treatment, the amount of sludge produced in the sewage treatment process also increases sharply [1]. At present, the sludge dewatering process is sludge thickening and then mechanical dewatering after conditioning, which is difficult to reduce the moisture content below $65 \%$. The feasible method is the sludge drying technology in order to increase sludge deep dewatering. Thermal drying is the most widely utilized sludge drying technology nowadays. In order to obtain higher treatment efficiency with lower cost, in addition to systematic optimization and mechanism study of the established drying process, it is equally important to improve the exogenous conditions in order to achieve greater breakthrough [2]. The two significant exogenous factors in the sludge drying system are heat source and the physicochemical properties of sludge. Ido [3] proposed the idea of utilizing waste heat of flue gas to dry municipal sludge. For the sludge, essential pretreatment such as adding appropriate conditioner can also effectively reduce the subsequent consumption of thermal energy.

Natural fiber has the characteristics of large specific surface area, well hydrophilicity and porous structure, so it can be used in the pretreatment before sludge drying. Rice straw fiber is a typical renewable biomass resource, which has the advantages of degradable and widely sourced. There are more than 700 million tons of crop stalks in China every year, but only $30 \%$ reused [4]. As a sludge dewatering conditioner, rice straw fiber could improve sludge dewatering efficiency and avoid secondary pollution. As an exogenous additive of sludge drying, the length of the straw and the diameter of the sludge just form a support structure, making the sludge foam stable [5-6]. In this study, rice straw fiber was collected as a conditioner for adding to the sludge. The effects of its dosage, particle size and operating temperature on the sludge drying rate and water migration were investigated, hoping to explore the role of straw fiber in the sludge drying process.

\section{Methods and materials}

\subsection{Activated sludge}

The dewatered sewage sludge was obtained from a local municipal WWTP in Changsha, China. This plant treats $200,000 \mathrm{~m}^{3} / \mathrm{d}$ of wastewater (almost all domestic sewage) using the oxidation ditch process. Sludge was dewatered by belt filter presses with addition of cationic flocculating agents. The moisture content of dewatered sludge was $84.0 \%$, and the density was $1.05 \mathrm{~g} / \mathrm{cm}^{3}$.

\subsection{Rice straw fibers preparation}

Rice straw fibers were collected from the surrounding countryside. First, rough crushing was carried out and then samples were screened for different mesh. The straw grain size was classified into four categories: larger than 8 mesh, 8-35 mesh, 35-80 mesh, less than 80 mesh, which was shown in figure 1.

\footnotetext{
a Corresponding author: gavinhj@163.com
} 


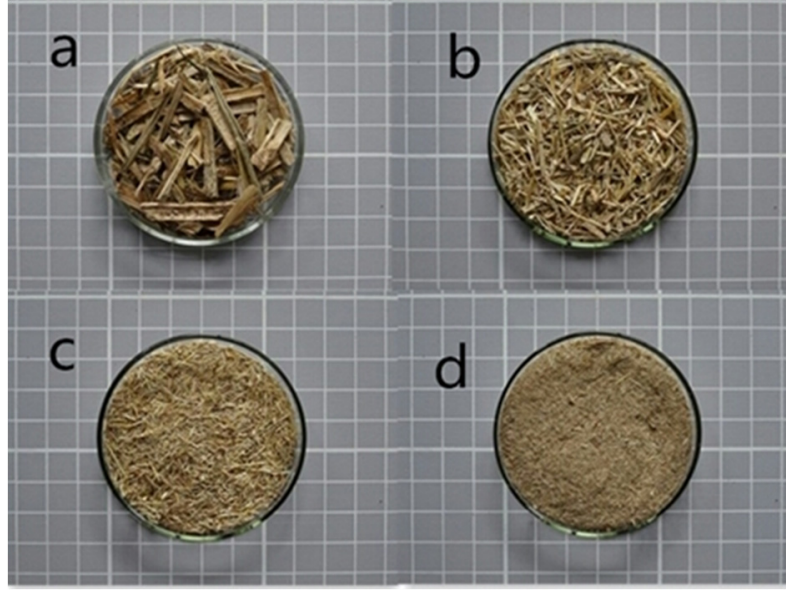

Figure 1. Straw fiber with different particle size(a. $>8$ mesh, b.8-35 mesh, c.35-80 mesh, d. $<80$ mesh)

\subsection{Sludge drying process}

The drying temperature was set at $30^{\circ} \mathrm{C}, 40^{\circ} \mathrm{C}, 50^{\circ} \mathrm{C}$, and $60^{\circ} \mathrm{C}$. The humidity in the drying oven was $20 \%$, and the air circulation rate was $0.2-0.4 \mathrm{~m} / \mathrm{s}$. Once $5.0 \mathrm{~g}$ of sludge sample was accurately weighed and spread out on a round glass dish, and straw was added into it according to a certain ratio. Then the sludge mixture was dried at the corresponding temperature. Measured and recorded the mass of the sample every $20 \mathrm{~min}$ until it remained unchanged.

\subsection{Sludge property analysis}

Sludge density was determined by the mean ratio of measured weight using one conical measuring cylinder with the full-loaded water weight of $206.6 \mathrm{~g}$. The moisture content of sludge was determined by the mass loss after drying at $105^{\circ} \mathrm{C}$ for $2 \mathrm{~h}$.

\section{Results and Discussion}

\subsection{Effect of dosage of conditioner and temperature on sludge drying}

Figure 2-5 showed the effect of different straw fiber dosage on sludge moisture content in different drying temperatures. The drying rate of the sludge with straw fiber was faster than that without straw fiber. Also, the more straw fiber added, the lower moisture content of the sludge was obtained, and the slower the drying rate was obtained. With the increase of drying time, the drying curves of each dosage intersected at a time point. Before the time point, the highest moisture content and the fastest drying rate presented when the straw fiber dosage was $10 \%$.

The results showed that the drying temperature is one of the important factors affecting the drying rate of sludge. When drying wet materials, there are usually two processes occurring in succession to control the drying rate, which are the constant drying stage and the slow drying stage. In the constant drying stage, the drying rate is constant and the material surface contains free water. When the sludge completely vaporized into the deceleration stage, the surface of the material does not contain enough free water. Until the heat into the material, it began to warm up and form a temperature gradient in the internal, so that the heat from the external to the internal, wet points from the internal migration to the surface. In this stage, most of capillary water and bound water are removed. With the drying time increased, the moisture content of the sludge with straw fiber gradually reduced. The higher the temperature was, the shorter the drying time and the faster the drying rate were shown. When the straw fiber was added $40 \%$ and the temperature was $60^{\circ} \mathrm{C}$, the sludge sample achieved drying equilibrium point was $180 \mathrm{~min}$, which was the shortest. When the temperature was $30^{\circ} \mathrm{C}$, the sludge sample achieved drying equilibrium point was $280 \mathrm{~min}$, which was the maximum. And the drying time required when the drying temperature is $40^{\circ} \mathrm{C}$ and $60^{\circ} \mathrm{C}$ was $260 \mathrm{~min}$ and $200 \mathrm{~min}$, respectively. Because higher drying temperature offered more energy to the drying system at the same time. Meanwhile, higher drying temperature enabled the moisture to shift to vapor and enhanced the vapor pressure of the air passing through the foamed sludge to carry more moisture out.

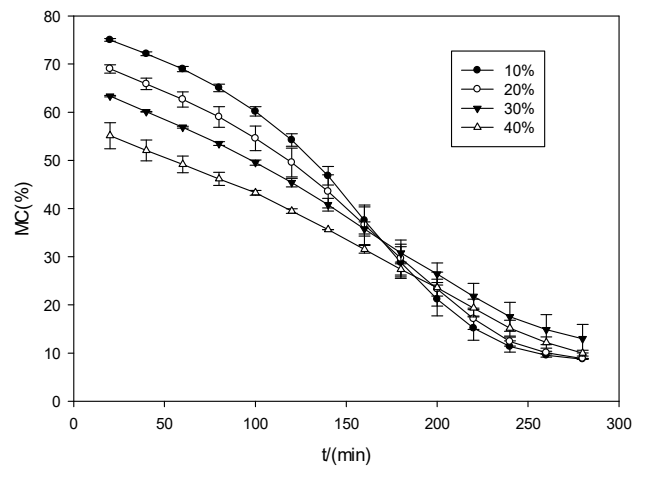

Figure 2. Effect of dosage on moisture content at $30^{\circ} \mathrm{C}$

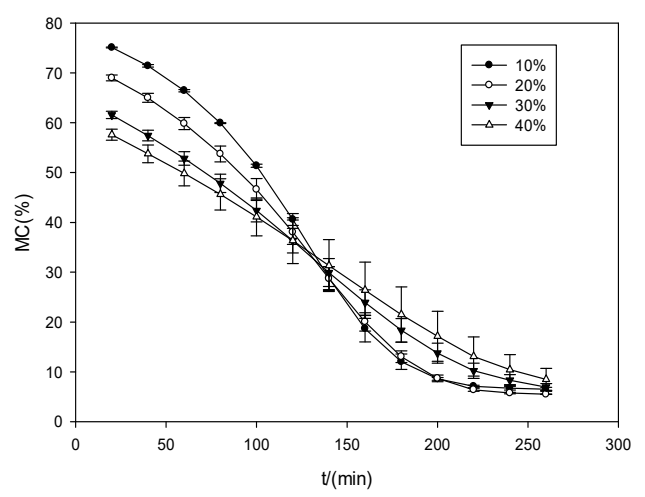

Figure 3. Effect of dosage on moisture content at $40^{\circ} \mathrm{C}$ 


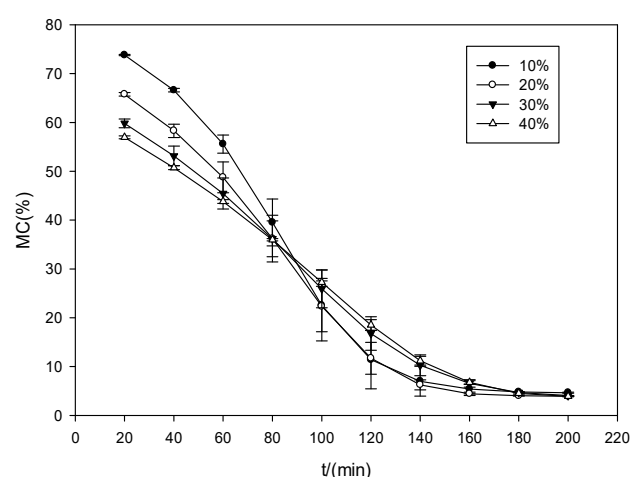

Figure 4. Effect of dosage on moisture content at $50^{\circ} \mathrm{C}$

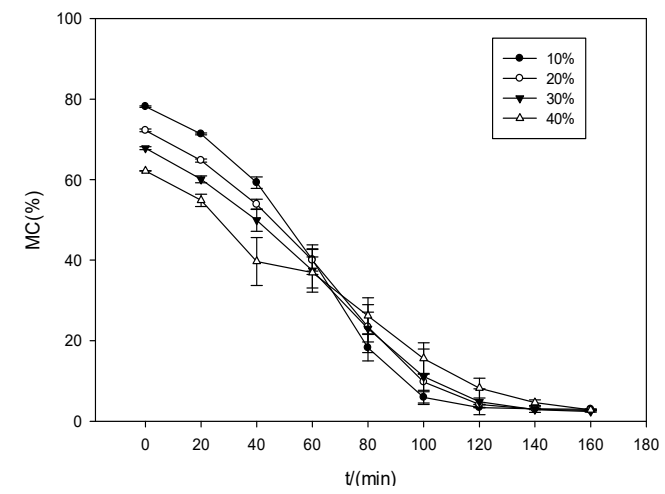

Figure 5. Effect of dosage on moisture content at $60^{\circ} \mathrm{C}$

\subsection{Effect of particle size of conditioner and temperature on sludge drying}

Figure 6-9 showed the effect of different straw fiber particle sizes on moisture content of sludge. As shown in Fig. 2, it is obvious that different straw fiber particle diameters had a significant effect on the drying of sludge in the drying temperatures of $30^{\circ} \mathrm{C}, 40^{\circ} \mathrm{C}, 50^{\circ} \mathrm{C}$, and $60^{\circ} \mathrm{C}$. After the foam treatment, the water holding capacity of the sludge was changed, part of the capillary water and bound water were converted into free water, which made the sludge more easily dry after the foaming treatment[7]. At the same time, when straw fibers were added into the sludge, the structure of the sludge was destroyed and the cell of the microorganisms in the sludge were ruptured promptly, making part of the internal water converted into free water. As the most easily removed moisture, the increase of free water content was also one of the reasons for the increase of drying rate of sludge with straw fiber added. In low temperature, after mixing straw fibers of smaller particle size and sludge, the drying time was shorter and the drying rate was faster. In the case of high temperature, the particle size of straw fibers did not have too much influence on the drying of sludge. The reason seems to be that the larger the particle size of the straw fiber was, the smaller the gap left after being evenly mixed with the sludge[8]. As a result, the smaller the area in contact with the air, the more difficult the drying process would be. But when the temperature was relatively high, this factor could be ignored. Therefore, when the temperature is lower, the particle size of the straw fiber needs to be considered, and a smaller particle size (8-35 mesh) is a better choice. When the temperature is higher, there is no need to consider the influence of straw fiber particle size on the drying of sludge. But the temperature should not be too high, otherwise, it will destroy the structure of the straw fiber and cause the loss of the important conditions originally required[9].

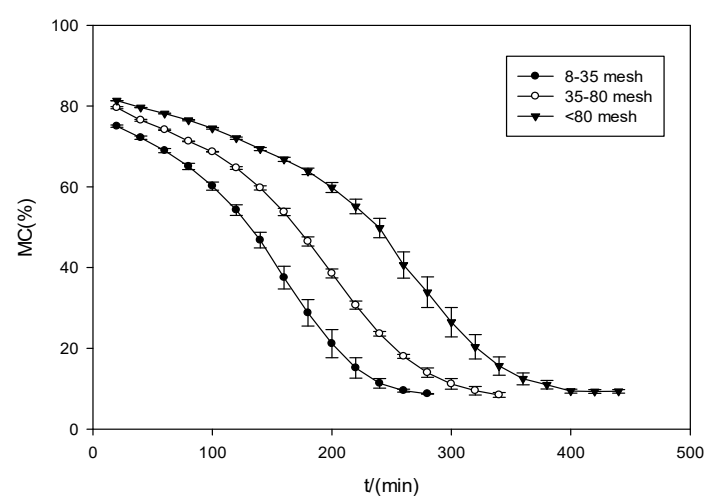

Figure 6. Effect of particle size on moisture content at $30^{\circ} \mathrm{C}$

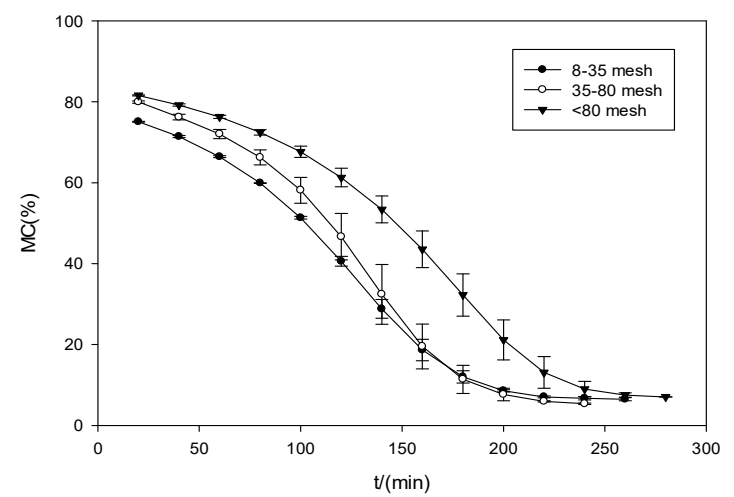

Figure 7. Effect of particle size on moisture content at $40^{\circ} \mathrm{C}$

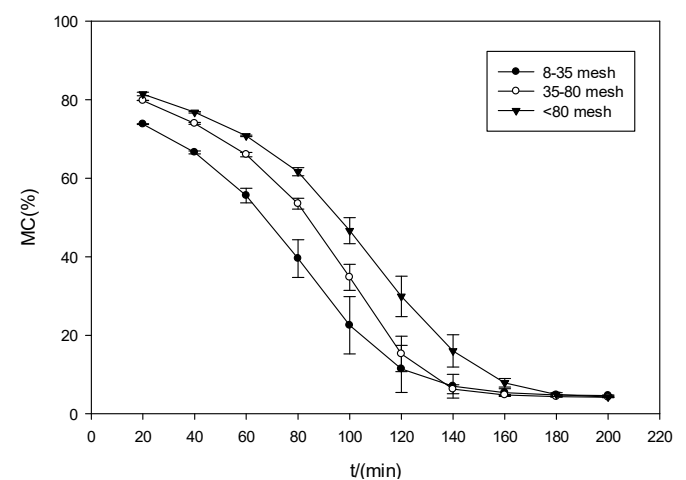

Figure 8. Effect of particle size on moisture content at $50^{\circ} \mathrm{C}$

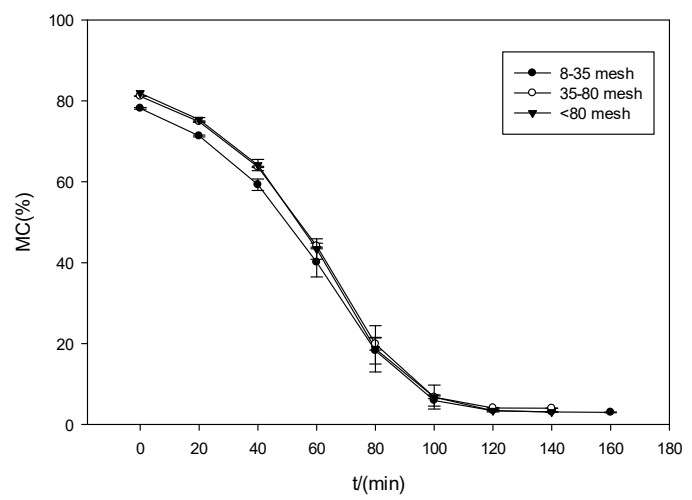

Figure 9. Effect of particle size on moisture content at $60^{\circ} \mathrm{C}$ 


\section{Conclusion}

In this study, rice straw fiber was collected as a conditioner for adding to the sludge. When the straw fiber was added $40 \%$ and the temperature was $60^{\circ} \mathrm{C}$, and the particle size of the straw fiber was 8-35 mesh, the drying rate of sludge was fastest. Rice straw fiber is an effective sludge drying conditioner. Under the same drying temperature and other external drying conditions, less sludge dries with less water to remove. In the actual sludge drying process, not only the drying time and drying rate of sludge, but also the addition amount of straw fiber and the disposal amount of sludge should be considered.

\section{Acknowledgments}

This work was financially supported by the National Natural Science Foundation of China (5180821 6), Natural Science Foundation of Hunan of China(2020JJ4643), the Research Project of Education Department of Hunan Province of China (18B406), Science and Technology International Cooperation Proje ct of Changsha City (KQ1907082).

\section{References}

1. J. Huang, Z.H. Yang, G.M. Zeng, H.L. Wang, J.W. Yan, H.Y. Xu, C.L. Gou, Water Res. 68, 667(2015)

2. H.L. Wang, Z.H. Yang, J. Huang, L.K. Wang, C.L. Gou, J.W. Yan, J. Yang, Water Sci. Technol. 69, 1859(2014)

3. S. Ido, B. Markus, Biosyst. Eng. 24, 1353(2006)

4. B.H. Guan, J. Yu, H.L. Fu, Water Res. 46, 425(2012)

5. C. Ratti, T. Kudra, Dry. Technol. 24, 1101(2006)

6. K. Alexandros, S. S. Athanasios, Waste Manage. 32, 1186(2012)

7. J.Vaxelaire, P.Cézac, Water Res. 38, 2215(2004)

8. R. Thuwapanichayanan, S.Prachayawarakorn, J. Food Eng. 86, 573(2008)

9. I. Bialobrzewski, M. Miks-Krajnik, J. Dach, M. Markowski, W. Czekala, K. Gluchowska, Waste Manage. 43, 72(2015) 